\title{
High Power Fibre Lasers: From Lab Experiments to Real World Applications
}

\author{
Michalis N. Zervas ${ }^{1,2^{*}}$ \\ 1: Optoelectronics Research Centre, University of Southampton, UK \\ 2: also with SPI Lasers, Southampton, UK \\ *mnz@orc.soton.ac.uk
}

Keywords: Fibre Lasers, Fibres, Fibre Nonlinearities, Material Processing

High performance, high power fibre lasers (FLs) are now well established as an extremely robust and reliable photon engine enabling a growing and diverse number of demanding industrial and medical applications [1-3]. Compared to rival technologies, such as $\mathrm{CO}_{2}$, LPSS, DPSS and disk lasers, FLs offer a number of unique characteristics that have resulted in their wide adoption in an increasing number of industrial sectors. In addition to enhancing existing applications, FLs have been very successful in enabling novel applications and thus continuing to increase their market share.

Due to their robust and all-fibre, all-guided architecture, FLs are unique in offering instant turn-on operation without the need of regular tuning and re-alignment. The inherently large surface-to-volume ratio facilitates heat removal and minimizes the external cooling requirements. Also, there are no thermal lensing effects, which in turn results in excellent beam pointing stability. The beam quality can be engineered by proper fibre core design to match the application requirements. FLs are usually pumped by combining a number of extremely robust, telecommunication-grade, single-emitter broad-stripe multimode pump diodes. This results in laser systems with long lifetime, maintenance-free operation. In addition, due to very low loss, monolithic all-fibre geometries, they show record optical-to-optical, electrical-to-optical and overall wall-plug efficiencies. Finally, FLs show very small and compact footprint that facilitates their system integration.

Key to harnessing the full potential of an all-fibre laser configuration is the adopted pumping scheme. One of the most efficient and manufacturable cladding-pumping technologies is an optically-coupled, multifibre assembly (GTWave ${ }^{\mathrm{TM}}$ ) [4], combining pump and signal (active) fibres and enables multiport, multipoint pump injection facilitating output power scalability. This modular approach results in robust, easily deployable CW/CWM fibre laser/amplifier systems with output power in the $10 \mathrm{~W}-1 \mathrm{~kW}$ ranges, covering the 1060nm and 1550nm wavelength regions [5]. In addition, all active fibres are designed to be photodarkening free, adding into system reliability and longevity. High power FLs are used in a number of industrial and medical applications, including stent tube cutting, disc drive spot welding, electronic stencil cutting, automotive plastic welding, medical piece part welding, rapid prototyping etc.

When in a MOPA configuration, optical fibres, being extremely high gain media (>50dB small-signal gain per stage) can adequately compensate for their inherently reduced capacity to store energy and can provide high performance pulsed systems. We will describe pulsed lasers with energies in the range of $1 \mathrm{~mJ}$ and peak power in excess of $15 \mathrm{~kW}$, at $25 \mathrm{kHz}$ repetition rate. A unique feature of these laser systems is the capability of producing high peak power pulses at very high rep rates $(>400 \mathrm{kHz})$. Such a laser has found widespread applications in a large number of demanding high-throughput marking and other material processing applications [6-8].

In this presentation, we consider the main issues related to power scaling in fibre lasers, such as suitable pumping schemes and pump requirements, fibre designs, limiting non-linear effects and parasitic issues like photodarkening. We will review the latest developments in the field of high power fibre lasers and present some of the new emerging applications. Finally, we will consider the main challenges regarding future developments and further power scaling.

Aknowledgment. The author acknowledges the technical contributions and full support of the entire SPI Lasers Engineering Group.

[1] Norman S, Zervas MN, Appleyard A, Durkin M, Horley R, Varnham M, Nilsson J, Jeong Y, "Latest development of high power fiber lasers in SPI", Proc. Of The Society Of Photo-Optical Instrumentation Engineers (SPIE) Vol. 5335 pp 229-237 (2004).

[2] Norman S, Zervas MN, "Fiber lasers - Fiber lasers prove attractive for industrial applications", Laser Focus World, Vol.43 Issue: $8, p$. 93, (2007).

[3] Horley R, Norman S, Zervas MN, "Progress and development in Fibre Laser technology", Proc. Of The Society Of Photo-Optical Instrumentation Engineers (SPIE), Vol. 6738, (2007).

[4] Grudinin AB, Payne DN, Turner PW, Nilsson J, Zervas MN, Ibsen M, Durkin MD, "Multifiber arrangement for high power fiber laser and amplifiers", US Patents 6826335, 7221822.

[5] Alam SU, Harker AT, Horley RJ , Ghiringhelli F, Varnham MP, Turner PW, Zervas MN, Norman SR, "All-Fibre, High Power, Cladding-Pumped 1565nm MOPA Pumped By High Brightness 1535nm Pump Sources", 2008 Conference On Lasers And ElectroOptics \& Quantum Electronics And Laser Science Conference, Vols. 1-9, pp. 1871-1872, (2008).

[6] Zervas MN, Durkin M, Ghiringhelli F, et al., "High peak power, high rep-rate pulsed fibre laser for marking applications", Proc Of The Society Of Photo-Optical Instrumentation Engineers (SPIE) Vol. 6102 p. Q1020 (2006).

[7] Vu KT, Malinowski A, Richardson DJ, Ghiringhelli F, Hickey LMB, Zervas MN, "Adaptive pulse shape control in a diode-seeded nanosecond fiber MOPA system", Optics Express, Vol. 14 Issue: 23 Pages: 10996-11001 (2006).

[8] Dupriez P, Piper A, Malinowski A, Sahu JK, Ibsen M, Thomsen BC, Jeong Y, Hickey LMB, Zervas MN, Nilsson J, Richardson DJ, "High average power, high repetition rate, picosecond pulsed fiber master oscillator power amplifier source seeded by a gainswitched laser diode at 1060 nm", Photonics Technology Letters, Vol. 18, pp. 1013-1015 (2006). 